\title{
Mapping the Root-Knot Nematode Resistance Gene $(R k)$ in Tobacco with RAPD Markers
}

\author{
H.-Y. Yi, R. C. Rufty, and E. A. Wernsman, Department of Crop Science; and M. C. Conkling, Department of \\ Genetics, North Carolina State University, Raleigh 27695-7620
}

\begin{abstract}
Yi, Y.-H., Rufty, R. C., Wernsman, E. A., and Conkling, M. C. 1998. Mapping the root-knot nematode resistance gene $(R k)$ in tobacco with RAPD markers. Plant Dis. 82:1319-1322.

Random amplified polymorphic DNA (RAPD) analysis was conducted to map the $R k$ gene in tobacco which conditions resistance to races 1 and 3 of the root-knot nematode, Meloidogyne incognita. Resistant burley tobacco genotype NC 528, containing the $R k$ gene, and the susceptible cultivar Ky 14 were screened with 1,500 random decamers. A low rate of genetic polymorphism $(<10 \%)$ was detected among these lines. Two populations $\left(\mathrm{F}_{1}\right.$ and $\left.\mathrm{F}_{3}\right)$ of maternally derived doubled haploid (MDH) lines of burley tobacco, developed from the cross NC $528 \times \mathrm{Ky}$ 14 , were used to map the $R k$ gene. NC 528 , Ky 14, three $R k$-resistant (Rk-R) DNA bulks, and three $R k$-susceptible (Rk-S) bulks generated from $\mathrm{F}_{1}$-derived $\mathrm{MDH}$ individuals were screened with the primers that amplified bands polymorphic between Rk-R and Rk-S lines. A total of 67 F1MDH lines and 59 F3MDH lines were screened with the primers that amplified bands polymorphic between Rk-R bulks and Rk-S bulks to confirm linkage between candidate markers and the $R k$ gene. Sixteen RAPD markers were positioned at six loci in a map 24.1 centimorgans long. Six RAPD markers, including one identified in the F3MDH population, were mapped at the $R k$ locus.
\end{abstract}

Additional keywords: disease resistance, linkage analysis, Meloidogyne incognita, Nicotiana tabacum

The root-knot disease caused by various species of Meloidogyne is one of the most damaging diseases in all tobacco (Nicotiana tabacum L.)-growing areas $(11,17)$. The most distinctive symptoms caused by this nematode are root galls and plant stunting. Classical methods to control this nematode include crop rotation, soil fumigation, and use of resistant tobacco cultivars. Planting resistant cultivars is environmentally sound, and can be the most economical method when durable, highly resistant cultivars are available. Tobacco plants containing the $R k$ gene, which conditions resistance to $M$. incognita (Kofoid and White) Chitwood races 1 and 3, show a hypersensitive response to nematode infection and usually develop no galls. Resistant tobacco lines can be selected by inoculating roots with either eggs or 2stage juveniles, growing plants for one or more life cycles of the nematode, and measuring the response. The conventional method of measuring damage caused by this nematode is to use a gall-index rating system (percent root area galled; 1). When this system is applied, resistant lines usu-

Corresponding author: R. C. Rufty

E-mail: becky_rufty@ncsu.edu

Accepted for publication 17 August 1998.

Publication no. D-1998-1013-03R

(C) 1998 The American Phytopathological Society ally show a gall index of zero. Nevertheless, since this nematode test is usually conducted either in the greenhouse or field, and since nematodes are sensitive to environmental effects, a large number of replications is required to evaluate plant genotypes accurately.

A simple test utilizing the $\mathrm{M}^{\mathrm{S}} \mathrm{N}^{\mathrm{R}}$ strain of potato virus $\mathrm{Y}\left(\mathrm{PVY}-\mathrm{M}^{\mathrm{S}} \mathrm{N}^{\mathrm{R}}\right)$ is widely used by breeders to select genotypes carrying the $R k$ gene $(16,19)$. This test is a simple detached-leaf assay in which rootknot-resistant genotypes produce a necrotic reaction in response to the virus, whereas root-knot-susceptible genotypes show no symptoms. This indirect inoculation method is $100 \%$ effective due to the pleiotropic effects of the $R k$ gene in response to PVY-M $\mathrm{M}^{\mathrm{S}} \mathrm{N}^{\mathrm{R}}$ (16). Nevertheless, molecular markers would be useful for identifying genotypes carrying multiple disease resistance genes without the need to conduct several inoculation experiments simultaneously. Utilization of molecular markers to identify root-knot-resistant lines would also enable plant breeders to select tobacco lines based on their genotypes without environmental interference. Molecular markers can also be valuable when selecting for disease resistance traits where the pathogen is difficult to obtain due to its biology or quarantine.

The random amplified polymorphic DNA procedure (RAPD; 18,21) has been used to map the genomes of several plant species $(3,14,15)$. RAPD markers tightly linked to agronomically important genes (mostly disease-resistance genes) have also been identified in several crops $(2,4,5,12)$. In mapping with RAPDs, homozygotes and heterozygotes in an $\mathrm{F}_{2}$ mapping population cannot be distinguished because RAPD markers are dominant in their inheritance. However, when used with backcrosses or highly homozygous populations such as near-isogenic lines or doubled haploid lines, RAPDs are fully informative whether the marker is linked in coupling or repulsion.

Bulked segregant analysis (BSA) is a method to identify molecular markers linked to a gene of interest without having to construct a map of the genome (13). By bulking DNA from individuals with the same phenotype, only the region of the gene of interest is compared for alternative alleles. Instead of screening dozens of individuals to test for linkage, DNA bulks with fewer than 10 individuals are normally screened with random primers, saving time and resources. Another advantage of BSA is that only polymorphic bands potentially linked to the gene of interest are scored.

The objective of this study was to map the region of the tobacco genome around the $M$. incognita resistance gene $(R k)$ in tobacco using the BSA procedure with RAPD markers.

\section{MATERIALS AND METHODS}

Plant material. Maternally derived doubled haploid (MDH) populations used in this study were developed by Wilhite (20) using the $N$. africana method. The MDH populations were originally developed to study genetic relationships such as linkage, epistasis, and pleiotropy among agronomically important traits (including root-knot nematode resistance) in burley or flue-cured tobacco lines (20). Chromosome-doubled plants were selfed to produce $67 \mathrm{~F}_{1}$-derived maternal-doubled haploid lines (F1MDHs; 19). In addition, 59 F3MDH lines were produced in the same manner from $\mathrm{F}_{3}$ plants arising from $\mathrm{F}_{2}$ fullsib families. The burley tobacco $\mathrm{MDH}$ lines used were produced from the cross NC $528 \times$ Ky 14. NC 528 is a burley breeding line highly resistant to races 1 and 3 of the root-knot nematode due to the presence of the $R k$ gene. This line was developed by crossing the flue-cured cultivar NC 95 to the burley cultivar Burley 21 and backcrossing the $F_{1}$ to Burley 21 to 
transfer the $R k$ gene. The burley cultivar Ky 14 is susceptible to this nematode. Root-knot nematode resistance showed Mendelian inheritance of a monogenic trait (1:1) in MDH populations (20).

DNA extraction. DNA was extracted from plant tissue by the procedure of Kochert et al. (7) with modifications as follows. Leaf tissue of 2- to 3-month-old plants was ground, suspended in $150 \mathrm{ml}$ of cold extraction buffer, and centrifuged at $400 \times g$ for $20 \mathrm{~min}$ at $4^{\circ} \mathrm{C}$. After chloroform-isoamyl alcohol was mixed with the crude nuclear preparation, the sample was centrifuged at $3,000 \times g$ for $30 \mathrm{~min}$ to obtain a clear supernatant. DNA was precipitated with cold isopropanol and hooked out with a glass rod. After rinsing in cold $70 \%$ ethanol, DNA was dried on several layers of laboratory tissue paper. Dry DNA was dissolved in $1 \times$ Tris-EDTA (TE) buffer containing RNase A, and was quantitated by measuring absorbance at $260 \mathrm{~nm}$.

RAPD analysis. Amplification reactions were carried out as described by Williams et al. (21) with modification. The $15-\mu l$ reaction mixture consisted of $1 \times$ reaction buffer (10 mM Tris-HCl, pH 8.3, $50 \mathrm{mM}$ $\mathrm{KCl}, 1.5 \mathrm{mM} \mathrm{MgCl}, 0.1 \%$ Triton-X); 100 $\mu \mathrm{M}$ each dATP, dCTP, dGTP, and dTTP; $10 \mathrm{ng}$ template DNA; $20 \mathrm{ng}$ primer; $1.2 \mu \mathrm{l}$ bovine serum albumin $(100 \mathrm{mM})$; and 1 unit Taq DNA polymerase (BoehringerMannheim, Indianapolis, IN). Reactions were prepared in a 96-well Falcon Microtest III Flexible Assay Plate (Becton Dickinson \& Co., Oxnard, CA), and amplification was performed in a PTC-100 Programmable Thermal Controller (MJ Research, Inc., Watertown, MA). An amplification cycle consisted of $1 \mathrm{~min}$ at $92^{\circ} \mathrm{C}, 1$ $\min$ at $35^{\circ} \mathrm{C}$, and $2 \mathrm{~min}$ at $72^{\circ} \mathrm{C}$. A total of 41 cycles was performed. Amplification products were analyzed by electrophoresis in $2 \%$ agarose gels ( $450 \mathrm{ml}$ gel/run) to which $8 \mu \mathrm{l} / \mathrm{gel}$ ethidium bromide (10 $\mathrm{mg} / \mathrm{ml}$ ) was added. Gels were run in a model A3 horizontal electrophoresis system (Owl Scientific, Inc., Cambridge, $\mathrm{MA}$ ), at $150 \mathrm{~V}$ for 4 to $6 \mathrm{~h}$. Gels were videographed (Stratagene Eagle Eye II, Stratagene, La Jolla, CA) under UV illumination and images were printed with a thermal printer.

Identification of RAPD markers linked to the $R \boldsymbol{k}$ gene-preliminary screening. The two parental lines were screened with 1,500 decamer random primers to make a selection of primers that detected polymorphism between the lines. A total of 800 random primers (kits $\mathrm{A}$ to $\mathrm{Z}$ and $\mathrm{AA}$ to $\mathrm{AN}, 20$ primers in each kit) were from Operon Technologies (Alameda, CA), and 700 primers (sets 1 to 7, 100 primers in each set) were from the University of British Columbia (Vancouver, Canada). The amplification reaction of the selected primers was repeated to confirm polymorphism.

Bulked segregant analysis of the $R k$ gene. Three root-knot-nematode-resistant bulks (Rk-R 1 to 3 ) and three root-knotnematode-susceptible bulks (Rk-S 1 to 3; 13) were prepared by pooling $10-\mu \mathrm{l}$ aliquots of DNA (200 ng/ $\mu \mathrm{l})$ of each F1MDH line according to their responses to the root-knot nematode. The number of lines in each bulk varied from 8 to 10 . Bulked DNA samples to be used for amplification were diluted to $2 \mathrm{ng} \mathrm{DNA} / \mu \mathrm{l}$. The six bulks and the parents of the mapping population were evaluated with the primers selected from the parental line evaluation to confirm cosegregation of polymorphic bands with the $R k$ gene. Based on evaluations of DNA bulks, 67 individual F1MDH lines, 59 F3MDH lines, and the 2 parents were analyzed with the cosegregating primers to confirm RAPD marker linkage to the $R k$ gene, and to estimate the genetic distance among the markers.

Evaluation of root-knot nematode response. A greenhouse test was conducted to evaluate directly the response of F1MDH and F3MDH lines to $M$. incognita, race 1. Plants were placed under natural light conditions with temperatures ranging from 24 to $29^{\circ} \mathrm{C}$. A completely randomized design with four replications was used for this test. Eggs of M. incognita were extracted from roots of tomato (Lycopersicon esculentum Mill cv. Rutgers) using the $\mathrm{NaOCl}$ method (6). The soil around each plant was inoculated with 10,000 eggs. Non-inoculated plants were placed randomly within the experimental plot to serve as monitors for cross contamination. NC 2326 and NC 95 were used as susceptible and resistant controls, respectively. Plants were harvested 3 months after inoculation. Inoculated plants that developed no galls were classified as nematode resistant and plants with galls were classified as susceptible.

Linkage analysis. MAPMAKER/EXP $3.0(8,9)$ was used to analyze the linkage relationship of RAPD markers detected from BSA. Data were entered using the "F2 backcross" format. Linkage was declared when a $\log$ of the likelihood ratio (LOD) threshold of 3.0 and recombination frequency of 0.40 were met. The Haldane mapping function was used.

\section{RESULTS}

Bulked segregant analysis. A low rate of genetic polymorphism $(<10 \%)$ was detected between the parental lines NC 528 and Ky 14 when screened with 1,500 primers. Only those primers that detected polymorphism between the nematode-resistant and -susceptible parental lines were used in screening the DNA bulks. A total of $67 \mathrm{~F} 1 \mathrm{MDH}$ lines were screened with 17 primers. Of these primers, 16 amplified bands showing patterns that matched the pedigree data. The RAPD bands that were amplified by these 16 primers were all linked to the $R k$ gene. Operon primer E-17 detected three markers linked to this gene. Two RAPD bands, OPR-11/560 (a band
560 bp long amplified by Operon primer R-11) and OPV-9/1560, that were polymorphic, were not linked to the $R k$ gene. Polymorphic band OPR-11/560 was absent in all three nematode-resistant bulks, and present in two of the three nematode-susceptible bulks. Primer OPV-9/1560 distinguished between nematode-resistant and -susceptible bulks. Primers E17/400, 377/540, AK3/630, E17/2000, P10/1200, $538 / 350,254 / 760$, and 482/700 detected markers linked in coupling phase to the $R k$ gene. Repulsion-phase markers were identified by primers D6/1000, E17/940, 293/740, 503/400,635/660, 20/1100, and $\mathrm{Z} 4 / 540$.

A low level of recombination was detected in the mapping population. Nearly all resistant lines had the banding pattern of the resistant parent, NC 528, and almost all the susceptible lines had the banding pattern of the susceptible parent, Ky 14. An exception was found in two F1MDH lines, 11-2 and 85962, which consistently showed a banding pattern conflicting with their phenotypes. In Wilhite's study (20), line 11-2 was phenotyped as resistant and 85962 was classified as susceptible. In this study, however, line 11-2 showed a susceptible banding pattern and 85962 showed a resistant banding pattern with all primers. In addition, line 851000, which was classified as nematode-susceptible by Wilhite (20), showed the resistant banding pattern for 11 of 15 RAPD markers linked to the $R k$ gene. It was speculated that either these lines were recombinants or the previous phenotype was not accurate. The nematode phenotype of these three lines was reexamined by greenhouse evaluation and showed that the previous phenotype of lines 11-2 and 85962 was incorrect. When inoculated with eggs of $M$. incognita, line 85962 produced no visible galls on roots and galls were formed on roots of line 112. Line 851000 was confirmed as root-knot susceptible. Therefore, it was determined that line 851000 was a recombinant. Since there was no doubt that the newly confirmed phenotype was the correct one, linkage analysis was conducted with the corrected phenotype data for lines 11-2 and 85962.

The same result was obtained from data on F3MDH lines. Two F3MDH lines, 151-9 and 153-19, showed contradiction between the original phenotypes reported by Wilhite (20) and data from our study. Line 151-9 was originally determined as nematode resistant and line 153-19 was classified as susceptible. When re-tested with the nematode, line 151-9 showed a susceptible response, whereas line 153-19 was resistant. Operon primer AC-15 amplified an additional marker for the $R k$ gene (OPAC$15 / 929$ ), and this marker confirmed that the original phenotype assessment was not correct. The marker was linked to the $R k$ gene in repulsion phase, and no re- 
combination was detected among F3MDH lines (data not shown).

The RAPD map of the $R k$ gene (Fig. 1) was 24.1 centimorgans (cM) long, and 16 RAPD markers were mapped at six loci. Six RAPD markers were mapped at the $R k$ locus. Since RAPD markers are inherited as dominant markers, dominant homozygotes and heterozygotes cannot be distinguished with these markers. However, when a coupling phase RAPD marker and a repulsion phase marker are closely linked, the information obtained from the two markers can be used to identify heterozygotes. In this study, Operon primer E17 generated one coupling and one repulsion phase marker cosegregating with the $R k$ gene. This primer may be used in a segregating population to distinguish homozygous resistant individuals from heterozygous individuals. The flanking marker, UBC-503/400, was $3.1 \mathrm{cM}$ from the gene.

\section{DISCUSSION}

A high proportion of RAPD markers were found to be linked to the $R k$ gene in different populations and different types of tobacco. The high linkage frequency may be a consequence of the introgression of the $R k$ gene by breeders and lack of recombination around this gene because it is of inter-specific origin and does not pair with the recessive $N$. tabacum allele.

When RAPD banding patterns were compared to the pedigree information, it was clear that considerable genetic variation was generated when the $R k$ gene was transferred from the flue-cured cultivar NC 95 to the burley cultivar, Burley 21 (10).

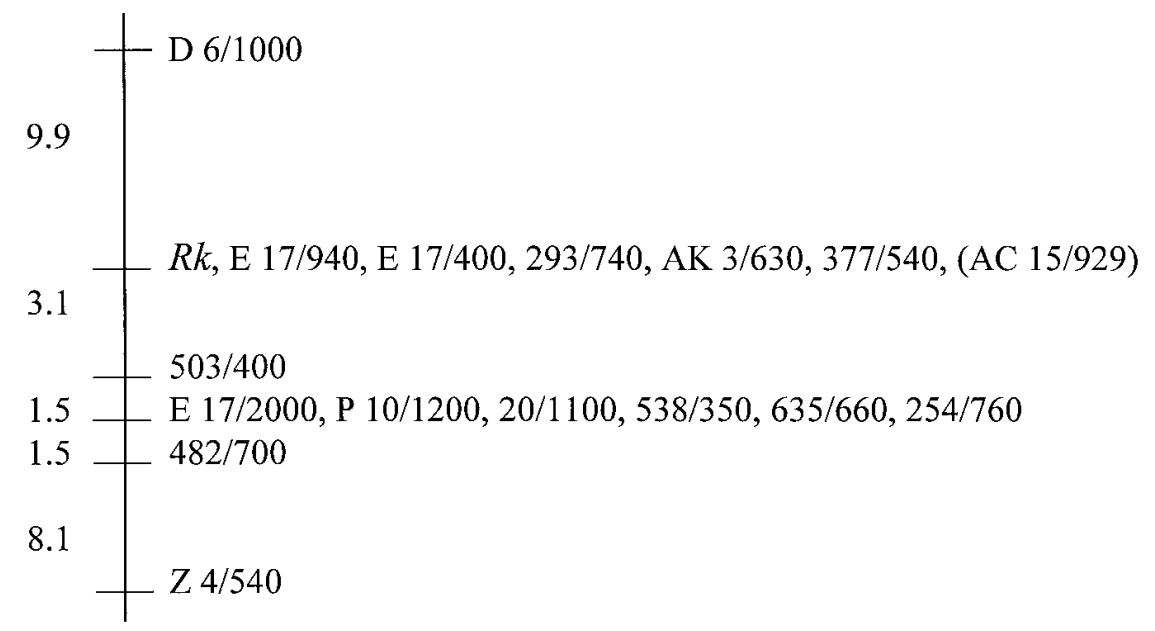

Fig. 1. Random amplified polymorphic DNA (RAPD) map of the region around the Meloidogyne incognita resistance gene $(R k)$ in tobacco. RAPD marker (AC 15/929) was identified in F3 population maternally derived doubled haploid (F3MDH) lines. The other markers were mapped in an F1MDH population. The markers amplified by Operon primers are designated as follows: D 6/1000 $=\mathrm{a}$ RAPD band of 1,000 base pairs (bp) amplified by Operon primer set D, number 6 , and so on; the RAPD markers amplified by primers from the University of British Columbia (UBC) are designated as: $377 / 540=$ a RAPD band of 540 bp amplified by UBC primer number 377, and so on. Map distances are given in centimorgans $(\mathrm{cM})$.
Our study indicates that RAPD markers, combined with highly homozygous populations and BSA, can be used to identify molecular markers tightly linked to agriculturally important genes in tobacco. Once these markers are identified, they can be used in a breeding program as a dependable selection tool across generations due to restricted recombination events in the region surrounding the genes.

\section{LITERATURE CITED}

1. Barker, K. R., Townshend, J. L., Bird, G. W., Thompson, I. J., and Dickson, D. W. 1986. Determining nematode population responses to control agents. Pages 283-287 in: Methods for Evaluating Pesticides for Control of Plant Pathogens. K. D. Hicky, ed. APS Press, St. Paul, MN.

2. Barua, U. M., Chalmers, K .J., Hackett, C. A., Thomas, W. T. B., Powell, W., and Waugh, R. 1993. Identification of RAPD markers linked to a Rhynchosporium secalis resistance locus in barley using near-isogenic lines and bulked segregant analysis. Heredity 71:177-184.

3. Grattapaglia, D., and Sederoff, R. R. 1994. Genetic linkage maps of Eucalyptus grandis and E. urophylla using a pseudo-testcross mapping strategy and RAPD markers. Genetics 137:1121-1137.

4. Halward, T., Stalker, H. T., LaRue, E. A., and Kochert, G. 1991. Genetic variation detectable with molecular markers among unadapted germplasm resources of cultivated peanut and related wild species. Genome 34:1013-1020.

5. Halward, T., Stalker, H. T., LaRue, E., and Kochert, G. 1992. Use of single-primer DNA amplifications in genetic studies of peanut (Arachis hypogaea L.). Plant. Mol. Biol. 18:315-325.

6. Hussey, R. S., and Barker, K. R. 1973. A comparison of methods of collecting inocula of Meloidogyne spp., including a new technique. Plant Dis. Rep. 57:1025-1028.

7. Kochert, G., Halward, T., Branch, W. D., and Simpson, C. E. 1991. RFLP variability in peanut (Arachis hypogaea L.) cultivars and wild species. Theor. Appl. Genet. 81:565-570.

8. Lander, E. S., Green, P., Abrahamson, S., Barlow, A., Daly, M. J., Lincoln, S. E., and Newburg, L. 1987. MAPMAKER: An interactive computer package for constructing primary genetic linkage maps of experimental and natural populations. Genomics 1:174181.

9. Lincoln, S., Daly, M., and Lander, E. S. 1992. Constructing genetic maps with MAPMAKER/EXP 3.0. Whitehead Inst. Tech. Rep. 3rd ed. Cambridge, MA.

10. Litton, C. C., Collins, G. B., and Legg, P. D. 1969. Registration of Ky 14 Tobacco. Crop Sci. 9:680.

11. Lucas, G. B. 1975. Root knot. Pages 59-86 in: Diseases of Tobacco. 3rd ed. Biological Consulting Associates, Raleigh, NC.

12. Martin, G. B., Williams, J. G. K., and Tanksley, S. D. 1991. Rapid identification of markers linked to a Pseudomonas resistance gene in tomato by using random primers and near-isogenic lines. Proc. Natl. Acad. Sci. USA 88:2336-2340.

13. Michelmore, R. W., Paran, I., and Kesseli, R. V. 1991. Identification of markers linked to disease resistance genes by bulked segregant analysis: A rapid method to detect markers in specific genomic regions by using segregating populations. Proc. Natl. Acad. Sci. USA 88:9828-9832.

14. Mudge, J., Anderson, W. R., Kehrer, R. L., 
and Fairbanks, D. J. 1996. A RAPD genetic map of Saccharum officinarum. Crop. Sci. 36:1362-1366.

15. Plomion, C., Bahrman, N., Durel, C. E., and O'Mally, D. M. 1995. Genomic mapping in maritime pine (Pinus pinster) using RAPD and protein markers. Heredity 74:661-668.

16. Rufty, R. C., Wernsman, E. A., and Powell, N. T. 1983. A genetic analysis of the association between resistance to Meloidogyne incognita and a necrotic response to infection by a strain of potato virus $\mathrm{Y}$ in tobacco. Phytopathology 73:1413-1418.

17. Shew, H. D., and Lucas, G. B. 1991. Compendium of Tobacco Disease. APS Press. St. Paul, MN.

18. Welsh, J., and McClelland, M. 1990. Fingerprinting genomes using PCR with arbitrary primers. Nucleic Acids Res. 19:303-306.

19. Wernsman, E. A., and Rufty, R. C. 1987. Tobacco. Pages 669-698 in: Principles of Cultivar Development. Vol. 2. Crop species.
Walter Fehr, ed. MacMillan Publishing Co. NY.

20. Wilhite, F. M. 1990. Selection and linkage investigations in maternally-derived doubledhaploid populations of tobacco. Ph.D. thesis Dept. Crop Sci. N. C. State Univ. Raleigh

21. Williams, J. G. K., Kubelik, A. R., Livak, K. J., and Rafalski, J. A. 1990. DNA polymorphisms amplified by arbitrary primers are useful as genetic markers. Nucleic Acids Res. 18:6531-6535. 